\title{
Circulatory effects of controlled arterial hypotension with trimetaphan (Arfonad) Experimental study in patients with left ventricular failure
}

\author{
SIGURD NITTER-HAUGE \\ From the Laboratory of Cardiology, Medical Department B, University Hospital, Rikshospitalet, Oslo \\ Norway
}

SUMMARY Although it appears that a pronounced improvement in cardiac performance may occur with vasodilator treatment in patients with pump failure, greater experience is needed to document fully the benefits and the limitations of this therapy. Each of the many unloading agents available today has characteristic and unique properties which may be beneficial in certain clinical settings.

In the present study, trimetaphan (Arfonad) infused in 10 patients with left ventricular failure ( 6 with coronary arterial disease and 4 with valvular heart disease) produced a prompt reduction in left ventricular filling pressure (mean pulmonary wedge pressure) from an average of 19.3 to $11.1 \mathrm{mmHg}$ and in mean arterial pressure from an average of 106.5 to $83.9 \mathrm{mmHg}$. Cardiac index was essentially unchanged (3.5 and 3.3 litres/min per $\mathrm{m}^{2}$ ). Heart rate was unchanged. Right atrial and pulmonary arterial pressure were reduced, principally because of a decrease in venous return as there was only a slight reduction in pulmonary vascular resistance. Thus, the principal circulatory effects of trimetaphan were a distinct reduction in left ventricular filling pressure and systolic arterial pressure, without a pronounced effect on cardiac output. There was no difference between patients with coronary arterial disease and valvular heart disease. Side-effects of the therapy were not observed. The beneficial effects of vasodilator therapy in the patients studied were probably related to a reduction in ventricular systolic wall tension (afterload) with a resulting decrease in myocardial oxygen consumption, and to a reduction in ventricular enddiastolic pressure which may improve subendocardial perfusion.

The present study also showed that patients with chronic ischaemic heart disease might have their arterial pressure reduced to very low levels without subjective or other evidence of myocardial ischaemia, indicating that their coronary perfusion must have remained adequate.

Vasodilator agents capable of reducing systemic vascular resistance have been shown to increase left ventricular stroke volume and cardiac output and improve left ventricular pump function (Chatterjee and Parmley, 1977). Because of an associated venous pooling effect, significant reductions in left venticular end-diastolic volume and pressure and in pulmonary venous pressure occur during vasodilator therapy. Hence, the two major objectives of treatment of pump failure-improvement in forward output and decreases in pulmonary venous pressure and congestion, can be achieved. Vasodilators such as sodium nitroprusside, phento-

Received for publication 28 September 1977 lamine, and nitroglycerin have been used with beneficial haemodynamic responses in treatment of pump failure complicating myocardial infarction (Gold et al., 1972; Chatterjee et al., 1973a; Kelly et al., 1973). Vasodilator therapy has also been useful for the treatment of pump failure when it is precipitated by mechanical defects such as severe mitral or aortic regurgitation (Chatterjee et al., 1973b; Miller et al., 1976).

Although most vasodilator agents produce similar haemodynamic effects, each unloading agent has characteristic and unique properties which confer relative advantages in different settings. In the present study, trimetaphan (Arfonad) was administered because of its rapid reduction in arterial 
pressures and the rapid reversal of the hypotensive effect when the infusion is discontinued. Trimetaphan produces hypotension primarily by ganglionic blockade, with resulting venous pooling of blood, but has direct vasodilating action as well (Randall et al., 1949). The drug produces minimal changes in heart rate, thus allowing the effects on cardiac output to be attributed chiefly to changes in stroke volume. Trimetaphan has previously been shown to improve impaired cardiac performance in patients soon after open intracardiac operation (Kouchoukos et al., 1972) and more recently in small series of patients with acute myocardial infarction (Shell and Sobel, 1974), or chronic coronary pump dysfunction (Williams et al., 1976).

\section{Subjects and methods}

Ten randomly selected patients (7 men and 3 women, age range 49 to 65 years, mean 57 years) with clinical evidence of chronic congestive heart failure and class 3 to 4 symptomatology were studied. Six had coronary artery disease, with more than 50 per cent stenosis on all the major coronary ateries, hypokinetic left ventricle, and reduced ejection fraction (14 to $40 \%$ (with one exception $68 \%$ )), and 4 valvular heart disease (severe aortic or mitral valve insufficiency) with cardiomegaly. The cardiac effects of trimetaphan were evaluated during elective diagnostic cardiac catheterisation. Informed consent was obtained from all subjects. No drugs were given during the last 24 hours before the investigation. Patients with valvular heart disease were receiving an inotropic agent (digitoxin) and this was continued up to the time of study. The patients were examined in the supine position in the overnight fasting state after premedication with $0.1 \mathrm{~g}$ allypropymal.

After a control period of 20 minutes during which the various haemodynamic variables were required to be constant, intravenous infusion of trimetaphan was started. Trimetaphan powder $250 \mathrm{mg}$ was diluted in $500 \mathrm{ml} 5$ per cent glucose, giving a 0.5 per cent solution. The rate of administration was adjusted to lower gradually intra-arterial systolic pressure by approximately 30 per cent and not below $80 \mathrm{mmHg}$. This reduction in pressure occurred between 5 and 10 minutes after the start of infusion; this also corresponded with the greatest decrease in left ventricular filling pressure, which was not permitted to fall below $6 \mathrm{mmHg}$. The dose varied between 0.50 and $0.75 \mathrm{mg} / \mathrm{min}$. When the desired blood pressures had been obtained, a stable circulatory state was achieved at a constant infusion rate of 10 minutes. Cardiac haemodynamic measurements were repeated during the continued trimetaphan administration. The values for the haemodynamic variables at the end of the infusion were compared with those at the end of the control period.

Standard electrocardiographic leads I and II were recorded during the whole examination on an Elema Mingograf at a paper speed of $50 \mathrm{~mm} / \mathrm{s}$. Systemic arterial pressure (AP) was monitored through a polyethylene catheter inserted in the femoral artery, and right atrial (RA), pulmonary artery (PA), and pulmonary capillary wedge (PCW) pressures were taken through a Cournand catheter, using EMT 35 Elema Schonander Stockholm (ES) transducers and a Mingograph 800 (ES) ink jet recorder. Ten consecutive beats were analysed and the average pressure used. Intravascular pressures were referred to the fourth intercostal space in the anterior axillary line. Cardiac output was determined according to the Fick principle, with mixed venous blood samples taken from the pulmonary artery. Blood oxygen content was determined spectrophotometrically and expired air was analysed in a Scholander apparatus. Calculations used to quantify cardiocirculatory variables also included: Cardiac index $(\mathrm{CI})=\mathrm{CO} / \mathrm{BSA}$ (litres/min per $\mathrm{m}^{2}$ ); stroke volume index $(\mathrm{SVI})=\mathrm{CI} /$ heart rate; stroke work index $\quad(\mathrm{SWI})=(\overline{\mathrm{AP}}-\overline{\mathrm{PCV}}) \times \mathrm{SVI} \times 0.0136$ $\left(\mathrm{gm} / \mathrm{m}^{2}\right)$; pulmonary vascular resistance $(\mathrm{PVR}=$ $(\overline{\mathrm{PA}}-\overline{\mathrm{PCV}}) / \mathrm{CO} \times 80$ (dynes $\left.\mathrm{s} \mathrm{cm}^{-5}\right)$ systemic vascular resistance $(\mathrm{SVR})=\overline{\mathrm{AP}}-\overline{\mathrm{RA}} / \mathrm{CO} \times 80$ (dynes $\mathrm{s} \mathrm{cm}^{-5}$ ), where 80 is the factor to convert $\mathrm{mmHg}$ to dynes $\mathrm{s} \mathrm{cm}^{-5}$.

Results are expressed as mean \pm SEM and were compared using Student's paired t test.

\section{Results}

Trimetaphan infusion at a constant rate reduced systolic and mean systemic arterial pressures in all subjects. The average systolic pressure of $161.4 \pm 9.1$ (SEM) fell to $123.7 \pm 7.0 \mathrm{mmHg}$ $(-33 \%)(\mathbf{P}<0.001)$, and mean arterial pressure from $106.5 \pm 5.2$ to $83.9 \pm 4.8 \mathrm{mmHg}(-22 \%)$ $(P<0.001)$ (Fig 1A). Left ventricular filling pressure declined in each subject, and PCW was reduced from a mean value of $19.3 \pm 1.8$ to $11.1 \pm$ $1.6 \mathrm{mmHg}(43 \%)(P<0.001)$ (Fig. 1B). The mean heart rate of $74.6 \pm 2.5$ was not changed significantly (Fig. 1C). Cardiac index tended to be unchanged or slightly decreased in most patients, and mean cardiac index decreased insignificantly from $3.5 \pm 0.4$ to $3.3 \pm 0.31 / \mathrm{min}$ per $\mathrm{m}^{2}(\mathrm{P}>0.05)$ (Fig. 1D). A slight increase in arteriovenous oxygen difference paralleled the profile of reduction in cardiac output. 

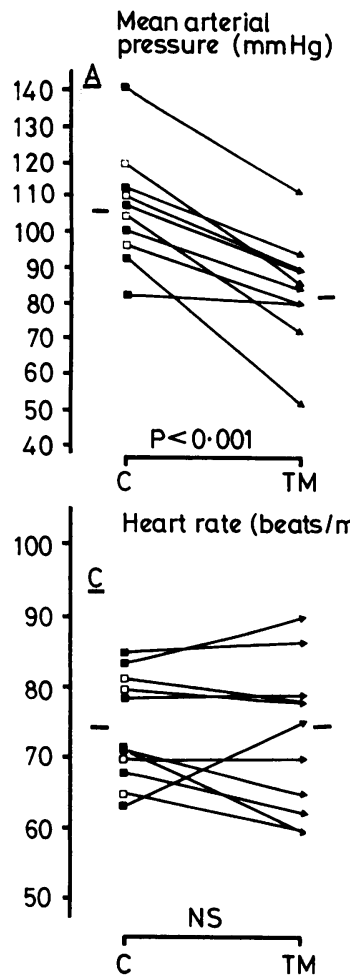
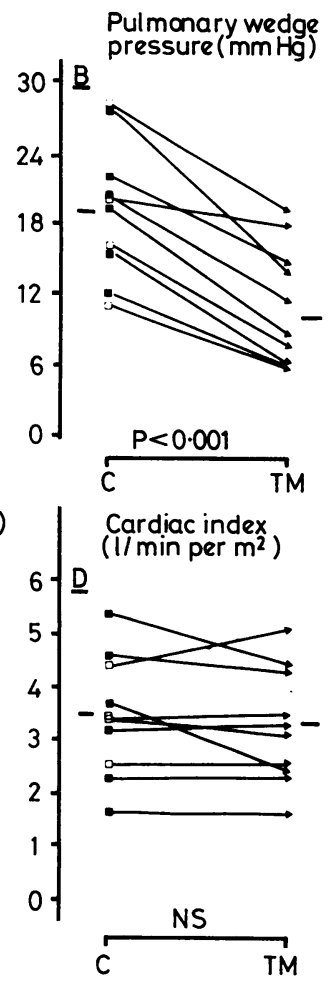

Fig. 1 Effects of trimetaphan on systemic mean arterial pressure $(A)$, pulmonary capillary wedge pressure $(B)$, heart rate $(C)$, and cardiac index $(D)$. C, control; $T M$, trimetaphan. Closed symbols: coronary artery disease. Open symbols: valvular heart disease. NS, not significant.

The constancy of cardiac output during infusion occurred at the same time as a fall in left ventricular filling pressure. A rise in cardiac output was observed combined with a fall in filling pressure in one single patient with valvular heart disease (Fig. 2).

Mean stroke work index was reduced significantly during infusion from a mean value of $56.9 \pm 8.1$ to $42.7 \pm 4.7 \mathrm{~g} \mathrm{~m} / \mathrm{m}^{2}(0.05>\mathrm{P}>0.01)$. As for the cardiac output, the direction of change in stroke work index was the same irrespective of the level to which left ventricular filling pressure fell during infusion (Fig. 3).

A slight reduction in systemic vascular resistance from an average of $1230.7 \pm 138.4$ to $1097.2 \pm$ $159 \cdot 2$ dynes $\mathrm{s} \mathrm{cm}-5$, and in pulmonary vascular resistance from an average of $123.5 \pm 25 \cdot 2$ to $94.8 \pm 13.6$ dynes $\mathrm{s} \mathrm{cm}^{-5}$ was not significant $(0 \cdot 10>\mathrm{P}>0.05)$.

Pulmonary arterial mean pressure decreased from $29.2 \pm 3.0$ to $18.8 \pm 2 \cdot 1 \quad \mathrm{mmHg} \quad(-36 \%)$ $(\mathrm{P}<0.001)$ and right atrial pressure from $6.8 \pm 1.7$ to $3.9 \pm 1.4 \mathrm{mmHg}(-43 \%)(0.01>\mathrm{P}>0.001)$.

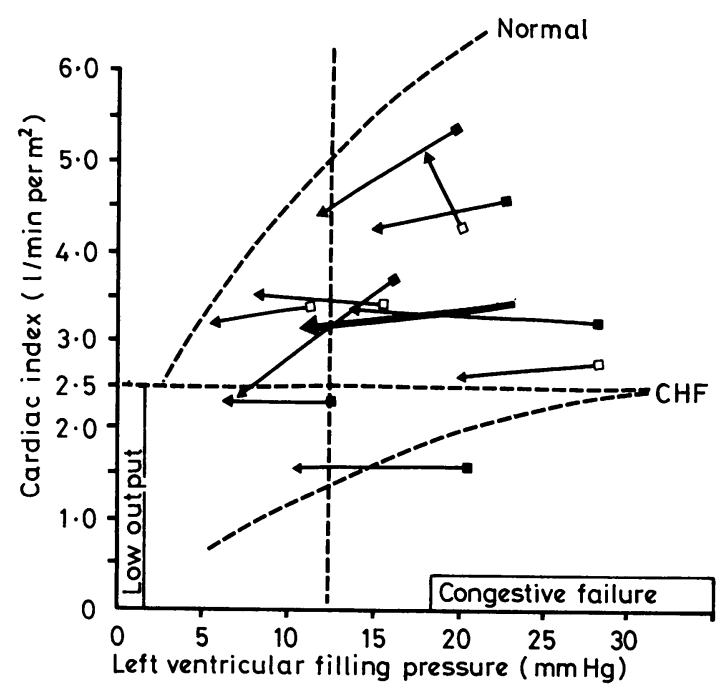

Fig. 2 Representative relations between cardiac output and left ventricular filling pressure in a normal heart, in a heart failing (CHF) because of decreased contractility, and in a failing heart before and after intravenous infusion of trimetaphan. The horizontal broken line indicates the lower limit of a normal cardiac output, and the vertical broken line signifies the upper limit of normal left ventricular filling pressure. Each dot represents baseline measurements, while the arrowheads represent measurements during trimetaphan infusion. The average results are shown by the thick arrow. Symbols as in Fig. 1.

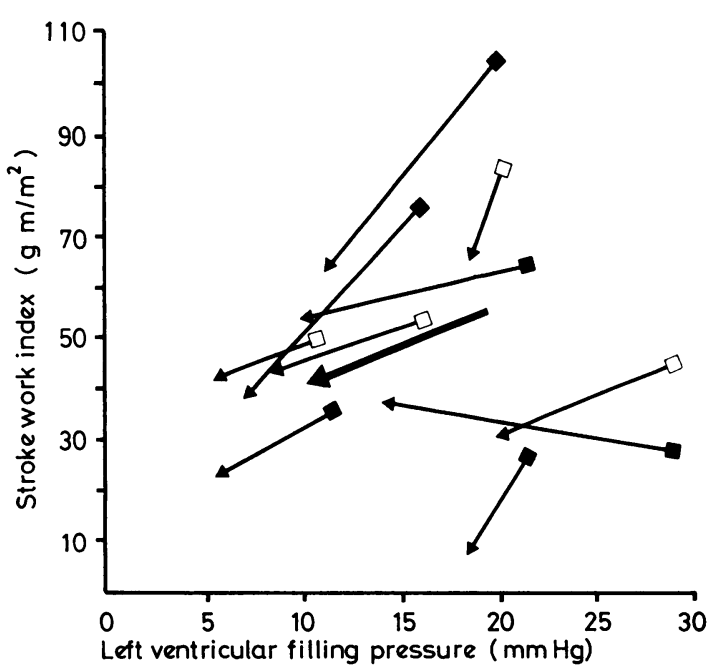

Fig. 3 Relation between stroke work index and left ventricular filling pressure before and during (arrows) trimetaphan infusion. Symbols as in Fig. 2. 


\section{Discussion}

It has been shown that trimetaphan and other ganglionic blocking agents have positive inotropic effects on the isolated muscle of the cat and on a hypodynamic heart-lung preparation in the dog (Lee and Shideman, 1958; Cook et al., 1969). Data confirming an inotropic action of trimetaphan in man are not available. Sobol et al. (1959) observed different effects on left ventricular function after infusion of trimetaphan and after administration of digitalis glycosides in patients with congestive heart failure. They concluded that the changes produced by trimetaphan were more probably the result of vasodilatation rather than of a change in the inotropic state of myocardium, and our results are in agreement with this. A decrease in right atrial and pulmonary arterial pressure paralleled the profile of reduction in pulmonary arterial wedge pressure. An important observation was that the decrease in pulmonary arterial pressure appeared to be principally related to the decreased venous return, since there was no significant decline in pulmonary vascular resistance. The effects on cardiac dynamics were the same in patients with reduced left ventricular function secondary to coronary arterial disease as in patients with pump failure precipitated by mechanical defects such as severe mitral or aortic valvular regurgitation. Therefore, it appears that in the present study trimetaphan was most efficacious in reducing the congestive manifestations of heart failure and of less benefit in increasing cardiac output. This is in accordance with observations previously published by Shell and Sobel (1974). When the cardiac output, however, is more definitely reduced than in the present study, the vasodilator properties of trimetaphan may also result in an augmentation of cardiac output, when the initial filling pressure is high (Kouchoukos et al., 1972; Williams et al., 1976). The actual patients with coronary arterial disease, however, like the large majority of patients with stable ischaemic heart disease, were characterised by normal to low cardiac output combined with a moderately increased left ventricular diastolic and often increased left ventricular systolic pressure as well. Under such haemodynamic circumstances, the oxygen saving effect of trimetaphan is produced by lowering of left ventricular systolic and diastolic pressures, with maintenance of a constant cardiac output and constant heart rate. Reduction of systemic vascular impedance permits greater muscle shortening and reduced systolic left ventricular wall tension and left ventricular end-diastolic volume; a fall in left atrial pressure resulting from a venodilator effect reduces left ventricular end-diastolic volume and encourages greater blood flow in the subendocardial tissue during diastole, and may relieve pre-existing ischaemia in the subendocardial myocardium (Salisbury et al., 1963; Hirshorn and Kaiser, 1970). A direct action of vasodilators on the coronary vasculature has been reported and blood flow to ischaemic segments of muscle may increase (Goldstein et al., 1974).

Side-effects of the drug were not observed in the present series. The arterial pressures were reduced to very low levels without any evidence of subjective or electrocardiographic signs of myocardial ischaemia, indicating that the circulation must have remained adequate in spite of hypotension. The fall in cardiac output in our patients was of little clinical significance and would be unlikely to effect adversely the supply of oxygen to the tissue. The observation that trimetaphan did not produce tachycardia in these patients may have important clinical implications since other vasodilators may be contraindicated in patients with compensated ischaemic heart disease who may develop tachycardia and increased myocardial oxygen requirements in response to vasodilatation. Trimetaphan may, therefore, deserve evaluation as a ventricular unloading agent since a reduction in blood pressure without an increase in heart rate should reduce myocardial oxygen demand (Braunwald 1969). Drugs such as nitroglycerin and nitroprusside which can produce rapid hypotension by direct vasodilatation also produce reflex changes in heart rate through the carotid sinus mechanism Nickerson, 1970). Administration of trimetaphan would be expected to serve as an appropriate agent in conjunction with positive inotropic therapy with digitalis, because it appears to be capable of counterbalancing increases in oxygen needs resulting from increased contractile state.

\section{References}

Braunwald, L. (1969). The determinants of myocardial oxygen consumption. Physiologist, 12, 65-93.

Chatterjee, K., and Parmley, W. W. (1977). Vasodilator treatment for acute and chronic heart failure. British Heart Fournal, 39, 706-720.

Chatterjee, K., Parmley, W. W., Ganz, W., Forrester, J., Walinsky, P., Crexells, C., and Swan, H. J. C. (1973a). Hemodynamic and metabolic responses to vasodilator therapy in acute myocardial infarction. Circulation, 48, 1183-1193.

Chatteriee, K., Parmley, W. W., Swan, H. J. C., Berman, G., Forrester, J., and Marcus, H. S. (1973b). Beneficial effects of vasodilator agents in severe mitral regurgitation due to dysfunction of subvalvular apparatus. Circulation, 48, 684-690.

Cook, W. A., Schwartz, D. L., and Bass, B. G. (1969). Arfonad therapy: hemodynamic responses and control. Annals of Thoracic Surgery, 7, 322-332. 
Gold, H. K., Leinbach, R. C., and Sanders, C. A. (1972). Use of sublingual nitroglycerin in congestive failure following acute myocardial infarction. Circulation 46, 839-845.

Goldstein, R. E., Stinson, E. B., Scherer, J. L., Seningen, R. P., Grehl, T. M., and Epstein, S. E. (1974). Intraoperative coronary collateral function in patients with coronary occlusive disease: nitroglycerin responsiveness and angiographic correlations. Circulation, 49, 298-308.

Hirshorn, S., and Kaiser, G. A. (1970). The effects of changes in left ventricular end-diastolic pressure on the distribution of coronary blood flow and on the electrical activity of the heart. Current Topics in Surgical Research, 2, 463-475.

Kelly, D. T., Delgado, C. E., Taylor, D. R., Pitt, B., and Ross, R. S. (1973). Use of phentolamine in acute myocardial infarction associated with hypertension and left ventricular failure. Circulation, 47, 729-735.

Kouchoukos, N. T., Sheppard, L. C., and Kirklin, J. W. (1972). Effect of alterations in arterial pressure on cardiac performance early after open intracardiac operations. Fournal of Thoracic and Cardiovascular Surgery, 64, 563-572.

Lee, W. C., and Shideman, F. E. (1958). Inotropic action of hexamethonium. Circulation Research, 6, 66-71.

Miller, R. R., Vismara, L. A., Williams, D. O., Amsterdam, E. A., and Mason, D. T. (1976). Effects of ventricular unloading with nitroprusside in severe aortic regurgitation: reduced regurgitant volume and improved cardiac performance (abstract). American fournal of Cardiology, 37, 156.

Nickerson, M. (1970). Vasodilator drugs. In The Pharma- cological Basis of Therapeutics, 4th ed., pp. 745-763. Ed. by L. S. Goodman and A. Gilman. Macmillan, New York.

Randall, L. O., Peterson, W. G., and Lehmann, G. (1949). The ganglionic blocking of thiophanium derivatives. fournal of Pharmacology and Experimental Therapeutics, 97, 48-57.

Salisbury, P. F., Cross, C. E., and Rieben, P. (1963). Acute ischemia of inner layers of ventricular wall. American Heart fournal, 66, 650-656.

Shell, W. E., and Sobel, B. E. (1974). Protection of jeopardized ischemic myocardium by reduction of ventricular afterload. New England fournal of Medicine, 291, 481-486.

Sobol, B. J., Kessler, R. H., Rader, B., and Eichna, L. W. (1959). Cardiac, hemodynamic and renal functions in congestive heart failure during induced peripheral vasodilatation; relationship to Starling's law of the heart in man. Fournal of Clinical Investigation, 38, 557-578.

Williams, D. O., Miller, R. R., and Mason, D. T. (1976). Effectiveness of trimethaphan (Arfonad) in the therapy of heart failure complicating coronary artery disease. Clinical Research, 24, 622A.

Requests for reprints to Dr Sigurd Nitter-Hauge, Laboratory of Cardiology, Medical Department B, University Hospital, Rikshospitalet, Oslo 1, Norway. 